\title{
Focus on the potential role of ficlatuzumab in the treatment of non-small cell lung cancer
}

\author{
This article was published in the following Dove Press journal: \\ Biologics:Targets and Therapy \\ I March 2013 \\ Number of times this article has been viewed
}

\author{
Manolo D'Arcangelo ${ }^{1,2}$ \\ Federico Cappuzzo ${ }^{2}$ \\ 'Cancer Center, University of \\ Colorado, Aurora (CO), USA; \\ ${ }^{2}$ Department of Oncology, Istituto \\ Toscano Tumori, Ospedale Civile, \\ Livorno, Italy
}

Correspondence: Federico Cappuzzo Istituto Toscano Tumori, Ospedale Civile di Livorno, Viale Alfieri 36,

57100-Livorno, Italy

Tel +3905862231 89

Fax +390586 223457

Email f.cappuzzo@gmail.com

\begin{abstract}
Lung cancer treatment has rapidly changed in the last few years thanks to novel insights into cancer biology. Several biomarkers and signaling pathways have been recognized as conceivable targets for treatment, and among them is the mesenchymal-epithelial transition/ hepatocyte growth factor (c-MET/HGF) axis. Alterations in the $c-M E T$ gene and aberrations of MET and HGF expression impact on lung cancer prognosis and are involved in resistance to epidermal growth factor receptor (EGFR) inhibitors in non-small cell lung cancer (NSCLC) patients harboring activating EGFR mutations. Several anti-MET and anti-HGF strategies are currently under investigation, including monoclonal antibodies. Ficlatuzumab is a monoclonal antibody directed against HGF that is currently under investigation in NSCLC. The aim of the present review is to critically review available data on HGF and ficlatuzumab in NSCLC.
\end{abstract}

Keywords: non-small cell lung cancer, MET, hepatocyte growth factor, ficlatuzumab, AV-299

\section{Introduction}

Lung cancer is a big killer in oncology, accounting for 1.3 million deaths per year worldwide. ${ }^{1}$ This disease includes two major histologic categories: small-cell lung cancer (SCLC, 15\%-20\% of cases) and non-small cell lung cancer (NSCLC, 80\%-85\% of cases) including adenocarcinoma, squamous cell carcinoma and large cell carcinoma. Beyond histologic aspects, lung cancer differs by the molecular aberration at the base of its pathogenesis and sustenance. Several oncogenic alterations in the genetic code and protein expression have so far been identified as conceivable targets for treatment. These molecular aberrations define subsets of patients with specific prognosis and outcome following treatment. Epidermal growth factor receptor (EGFR) gene mutations can be detected in 10\%-15\% of Caucasians and in up to $40 \%$ of Asian NSCLC patients. Soon after their discovery in 2004, they were recognized as the principal biomarker in lung adenocarcinoma predicting response to treatment with the EGFR tyrosine kinase inhibitors (TKI). ${ }^{2}$ Seven phase III trials including thousands of patients treated with gefitinib, erlotinib, or afatinib, clearly demonstrated that EGFR TKI are the best option as first-line therapy for EGFR mutated NSCLC. ${ }^{3-9}$ Disease control can be reached in up to $90 \%$ of mutant individuals, but none of them can be definitively cured and progression of disease inevitably occurs. Moreover, a consistent proportion of patients show primary resistance to EGFR inhibitors, even in the presence of EGFR activating mutations. Resistance is usually determined by secondary genomic alterations in the target kinase altering the physical or biochemical properties of the receptor and by the 
activation of collateral pathways. In $50 \%$ of cases a secondary gatekeeper mutation in the EGFR gene (T790M, D761Y) is responsible for acquired resistance. ${ }^{11-13}$ An additional $20 \%$ of refractory patients harbor overexpression of another tyrosine kinase receptor, the mesenchymal-epithelial transition (MET) receptor, which allows inhibition of the EGFR pathway to be bypassed. ${ }^{14,15}$ Some preclinical studies described a correlation between EGFR TKI resistance and overexpression of the c-MET ligand, hepatocyte growth factor (HGF). ${ }^{16}$ Several strategies to overcome resistance to EGFR TKI are being explored in preclinical and clinical trials. In case of a secondary mutation, irreversible TKI, ${ }^{9}$ heat shock protein 90 inhibitors, ${ }^{17}$ or combined treatment with anti-EGFR antibodies ${ }^{18}$ are under evaluation. Several MET inhibitors have so far been developed including monoclonal antibodies (ornatuzumab) and small molecule inhibitors (crizotinib, foretinib, cabozantinib, GCD265, tivantinib). ${ }^{19-24}$ Another possible strategy under evaluation is the blockade of HGF by competitive antagonists (NK4) or specific antibodies (AMG102/rilotumumab, AV-299/ ficlatuzumab). ${ }^{25,26}$ In this review we will describe the c-MET/ HGF signaling pathway in NSCLC, HGF expression as a resistance mechanism to EGFR TKI, and the possible role of HGF inhibition in the treatment of lung cancer patients, focusing specifically on ficlatuzumab.

\section{c-MET/hepatocyte growth factor axis and lung cancer}

The $c-M E T$ oncogene was first identified in the mid 1980s. It encodes a member of the receptor tyrosine kinase family and is structurally distinct from other components of the family. The receptor is a heterodimer composed of two subunits, the $\alpha$ - and $\beta$-chain (Figure 1). ${ }^{27,28}$ The $\alpha$-chain is completely extracellular and is linked to the $\beta$-chain by a disulphide bond. The $\beta$-chain includes three domains: an extracellular portion, a transmembrane domain, and a cytoplasmic one. The intracellular domain contains a juxtamembrane portion, a tyrosine kinase domain, and a carboxy-terminal tail..$^{27,28}$

Shortly after the discovery of MET, its physiological ligand, HGF or scatter factor, was identified. ${ }^{29}$ It is a plateletderived mitogen for hepatocytes and other normal cell types and a fibroblast-derived factor for epithelial cell scattering, ie, it induces random movement in epithelial cells. ${ }^{29-31} \mathrm{HGF}$ is a morphogen that induces transition of epithelial cells into a mesenchymal morphology. Both tumor and stromal cells have been identified as potential sources of HGF. ${ }^{32}$ Co-culture studies investigating tumor-stromal interaction demonstrated that fibroblast-dependent carcinoma cell growth and invasion is inhibited by anti-HGF antibodies, highlighting the importance of stroma-derived HGF in tumor sustenance and progression. ${ }^{33}$

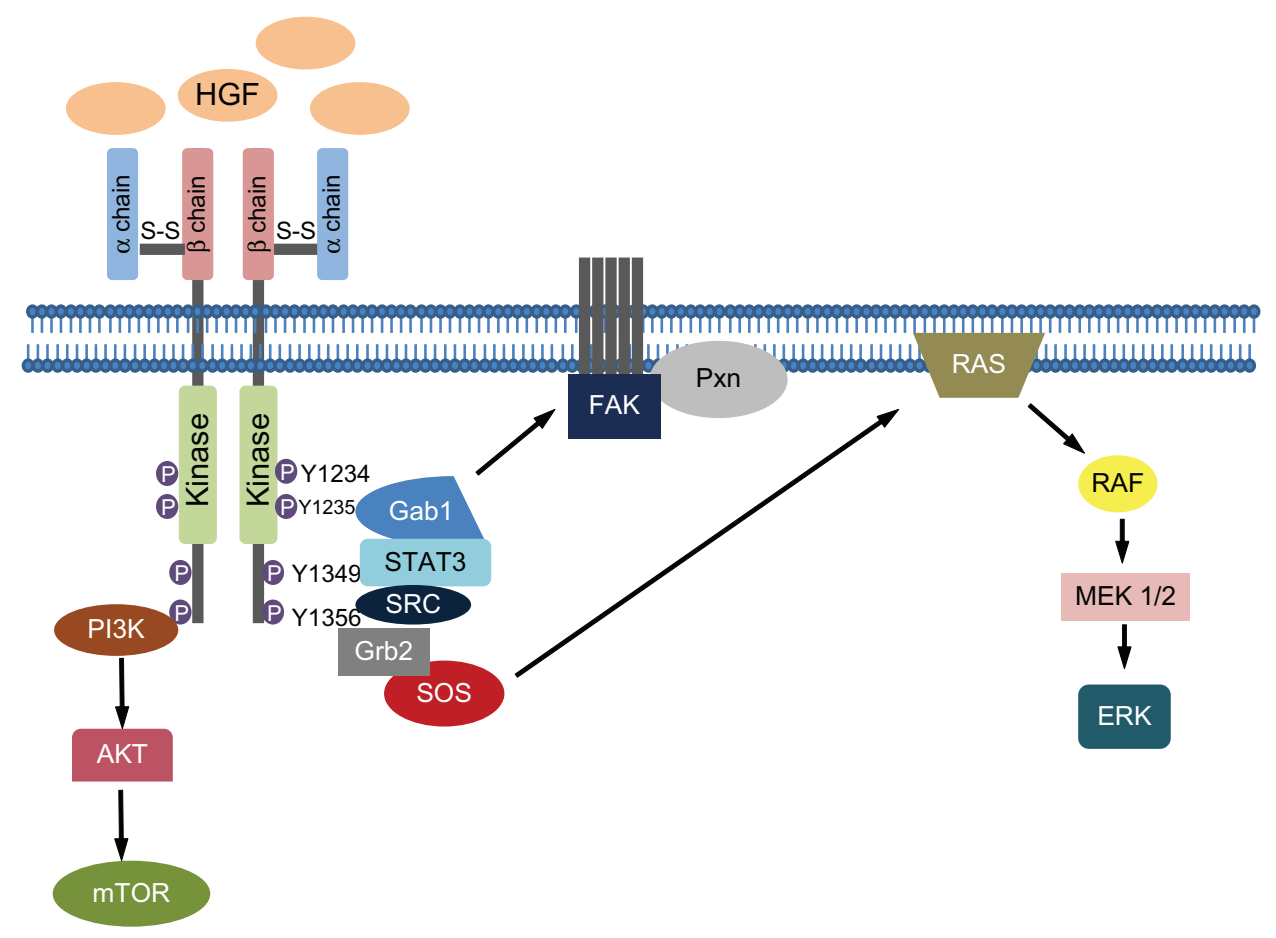

Figure I c-MET/HGF pathway.

Abbreviations: HGF, hepatocyte growth factor; PI3K, phosphoinositide 3-kinase; mTOR, mammalian target of rapamycin; Gab I; GRB-associated binding protein I; STAT3, signal transducer and activator of transcription 3; SRC, sarcoma; Grb2, growth factor receptor-bound protein 2; SOS, son of sevenless; FAK, focal adhesion kinase-I; Pxn, paxillin; RAS, rat sarcoma; RAF, rapidly accelerated fibrosarcoma; MEK I/2, MAPK/ERK kinase; ERK, extracellular signal regulated kinase. 
It is synthesized in an inactive form and then converted into a two chain heterodimer, including an amino-terminal domain $(\mathrm{N})$, four Kringle domains (K1-K4), and a serine protease homology domain. The N-K1 portion is responsible for MET binding and dimerization or multimerization. The joining of two or more c-MET receptors leads to phosphorylation of the tyrosine residues Y1234 and Y1235 in the tyrosine kinase domain, and phosphorylation of the residues Y1349 and Y1356 near the carboxy-terminal tail. ${ }^{34}$ The phosphorylation of the carboxy-terminal tail forms a multifunctional docking site that recruits intracellular adapters and substrates such as STAT3, Grb2, Gab1, PI3K, Shc, Src, Shp2, and Shp $1 .{ }^{35}$ Thus, several pathways involved in proliferation, survival, cell motility, invasion, and metastasis are activated. Interestingly, c-MET activation leads to the recruitment of effectors involved in the epithelial-mesenchymal transition through RAS/MAPK signaling and the FAK/paxillin complex (Figure 1).

Deregulation of c-MET/HGF signaling may result in carcinogenesis in several solid tumors. ${ }^{36,37}$ The most common mechanism of activation is c-MET protein expression due to transcriptional upregulation in the absence of gene amplification. ${ }^{38}$ Receptor overexpression can also be determined by gene amplification. ${ }^{39}$ Another rare mechanism of activation of the axis is by mutation of the $c-M E T$ gene. ${ }^{38}$ Kinase activation may be ligand independent, but in cancer it is mainly caused by binding of the ligand. Even in the case of $c-M E T$ activating mutations, $\mathrm{HGF}$ is needed to start the catalytic activity of the receptor. ${ }^{40} \mathrm{HGF}$ plays a fundamental role in the c-MET axis in cancer as it can act either as a paracrine factor, causing positive feedback leading to $c-M E T$ transcription, ${ }^{41}$ or act by an autocrine mechanism. ${ }^{42,43}$

$c-M E T$ gene amplification and overexpression have been associated with poor patient outcome in several studies. ${ }^{44,45}$ The concentration of HGF in serum or cancer tissue was associated with progression of disease in many cancer types including breast, ${ }^{43,46,47}$ gastric, ${ }^{48}$ bladder, ${ }^{49}$ colorectal, ${ }^{50}$ SCLC,${ }^{51}$ and myeloma. ${ }^{52}$ Several studies on NSCLC reported intratumoral and plasma HGF levels to be prognostic indicators. ${ }^{53-56}$ Two research groups analyzed the intratumoral levels of HGF in 56 and 183 resected NSCLC respectively and found an inverse correlation between HGF levels and overall survival, ie, individuals with high levels of intratumoral HGF were likely to have a worse prognosis. ${ }^{53,54}$ More recently, Hosoda et $\mathrm{al}^{55}$ studied plasma HGF levels in 25 resected NSCLC, revealing a better outcome in terms of both disease free survival $(P=0.032)$ and overall survival $(P=0.020)$ for patients with lower levels of HGF. In a similar study by Ujiie et al, ${ }^{56} \mathrm{HGF}$ plasma levels were a negative prognostic factor only for survival $(P=0.016)$ in a cohort of 109 surgically treated NSCLC patients.

\section{Role of HGF in EGFR TKI resistance and rationale for its blockade}

Other than a prognostic indicator, HGF seems to be involved in resistance to agents targeting the EGFR family, not only in lung cancer but also in other malignancies. Recently, our group investigated the role of MET and $H G F$ gene copy number in a large population of metastatic breast cancer patients treated with trastuzumab, an anti-HER2 antibody, and we showed that high $M E T$ and $H G F$ gene copy numbers associated with an increased risk of resistance to the antiHER2 therapy. ${ }^{57}$ In lung cancer, HGF can independently activate both PI3K/AKT and ERK signaling leading to drug resistance in the presence of EGFR TKI. Unlike MET amplified resistant cancers, HGF-mediated resistance occurs through Gab1 and does not involve HER3. ${ }^{58}$ In 2008, a Japanese group administered HGF to an adenocarcinoma cell line harboring a sensitizing EGFR gene exon 19 deletion and found that HGF induced resistance in a dosedependent manner. ${ }^{59}$ Higher levels of HGF can be detected in tumor specimens from NSCLC patients that are clinically resistant to gefitinib or erlotinib compared to pretreatment tumor specimens. Yano et $\mathrm{al}^{60}$ analyzed HGF expression in paraffin-embedded specimens from 93 EGFR mutant lung cancer patients and found a higher level of HGF expression in tumors with intrinsic and acquired resistance to EGFR TKI. In another study, Turke et $\mathrm{al}^{58}$ compared HGF levels in 16 NSCLC patients for which pre- and post-treatment specimens were available and found that HGF expression was significantly higher in the TKI resistant specimens than in the pretreatment specimens, supporting a role for HGF alone in promoting drug resistance. Both these research groups postulated that HGF may induce EGFR TKI resistance by selection of clones with MET gene amplification. ${ }^{58,60}$ Recently some researchers investigated whether HGF levels in blood may predict response to EGFR TKI treatment. Several studies analyzed HGF levels in serum from NSCLC patients treated with an EGFR TKI and not selected according to their EGFR mutational status, finding a strong correlation between serum HGF levels and outcome of treatment. ${ }^{61,63}$

Considering its properties and role as a determinant or promoter of resistance to EGFR TKI, HGF may represent a perfect candidate as a target for treatment. The growth factor is able to induce MET protein overexpression and its blockade may consequently avoid the development of this resistance mechanism in a consistent proportion of patients. 
Moreover, HGF can convert cancer cells from an epithelial to a mesenchymal phenotype and it is known that lung cancers expressing mesenchymal markers are more resistant to EGFR TKI treatment than tumors with an epithelial phenotype. ${ }^{64,65}$ A prominent question for all resistance mechanisms is whether they occur as a consequence of treatment or if they exist prior to treatment and are selected under therapy pressure. Growing evidence indicates that resistance mechanisms are already present in small clones of tumor cells, as in the case of secondary EGFR mutations ${ }^{58}$ and $M E T$ amplification. ${ }^{66}$ Therefore, treatment with a combination of an EGFR TKI and an anti-HGF or anti-MET agent, particularly in patients with evidence of $M E T$ amplification or HGF overexpression, could be more effective than an EGFR TKI alone. In addition, HGF and its receptor are clearly involved in the processes of invasion and metastasis and preclinical data suggest a synergistic effect of EGFR TKI and anti-MET agents, even in EGFR wild-type models. ${ }^{67}$ For all the listed reasons, anti-MET and anti-HGF strategies are currently under development in NSCLC and other malignancies.

Preclinical data suggested that HGF inhibition could be potentially effective against lung cancer. Okamoto et $\mathrm{al}^{68}$ examined the effects of adding an anti-HGF antibody (TAK-701) to gefitinib treatment in an EGFR mutant cell line engineered to stably express HGF. The combination suppressed cell growth by inhibition of phosphorylation of MET and of the downstream effectors of the EGFR pathway (EGFR, ERK, and AKT), indicating that autocrine c-MET/ HGF signaling contributes to gefitinib resistance. In athymic nude mice, the combination therapy of TAK-701 and gefitinib inhibited tumor growth in vivo. In another study, a different anti-HGF antibody (L2G7) was used in combination with gefitinib in HGF expressing mice in which lung tumors were induced by exposure to a carcinogen. ${ }^{69}$ The mean tumor number in the group treated with the combination of L2G7 and gefitinib was significantly lower than with single agents. Apoptosis was significantly higher in the group treated with combination therapy (17-fold) compared to a single agent (7.9- and 3.5-fold for L2G7 and gefitinib, respectively).

\section{Ficlatuzumab: current status and future directions}

Ficlatuzumab (SCH 900105 or AV-299, Aveo Pharmaceuticals, Inc, Cambridge, MA, USA) is a humanized IgG1 antibody that binds the HGF ligand with high affinity and specificity, thus inhibiting c-MET/HGF biological activities. Its pharmacokinetic profile is characterized by a doseproportional drug exposure with a low systemic clearance and a terminal half-life of $7-10$ days. ${ }^{70}$ In a phase I trial, ficlatuzumab monotherapy resulted in decreases of phosphoMET, phospho-ERK, phospho-AKT, and Ki67. ${ }^{71}$ The antitumor efficacy of ficlatuzumab was evaluated in paracrine models of a HGF-dependent NSCLC cell line xenografted into SCID mice engineered to produce human HGF. Ficlatuzumab monotherapy decreased tumor growth in a dose-dependent manner and led to significant reductions in phospho-c-MET and phospho-AKT levels, but produced a concurrent increase in phospho-EGFR levels. Therefore, ficlatuzumab was studied in combination with erlotinib or cetuximab, and the two combination treatments showed increased antitumor activity when compared to the single agents. ${ }^{71}$ The potent antitumor activity of the combination with EGFR inhibitors observed in preclinical models supported further development in NSCLC patients. In a phase I trial, ficlatuzumab was administered both as a single agent (in 24 patients) and in combination with erlotinib $150 \mathrm{mg}$ daily (in 13 patients) in 37 patients with solid tumors, and was well tolerated up to the maximum tested dose of $20 \mathrm{mg} / \mathrm{kg}$ every two weeks. ${ }^{72}$ The most common toxicities of ficlatuzumab monotherapy were fatigue, peripheral edema, headache, and diarrhea; skin rash and diarrhea were the major side effects of the combination treatment. Another phase Ib trial studied ficlatuzumab in association with gefitinib in 15 molecularly unselected Asian NSCLC patients. ${ }^{25}$ The recommended phase II dose was $20 \mathrm{mg} / \mathrm{kg}$ every two weeks for ficlatuzumab and $250 \mathrm{mg}$ daily for gefitinib. Among the twelve patients treated in the $20 \mathrm{mg} / \mathrm{kg}$ arm, five were EGFR TKI naïve and all of them reached a partial response. In the same treatment arm, stabilization of disease was observed in four cases and progression in three cases.

Recently, Mok et al presented the results of a randomized phase II trial comparing gefitinib as single agent versus the combination of gefitinib and ficlatuzumab. ${ }^{73}$ The study enrolled 188 Asian treatment naïve patients with lung adenocarcinoma not selected for EGFR mutational status, even if the study population had clinical characteristics frequently associated with the presence of EGFR mutations. The primary endpoint of the study was to compare the overall response rate between treatment arms. In the overall population there was no statistical difference in response rate (40\% for gefitinib arm versus $43 \%$ for the combination arm) or progression free survival (4.7 months versus 5.6 months in the gefitinib arm versus combination arm, respectively). Surprisingly, subgroup analyses showed that combination therapy was more effective in patients with low MET expression. In particular, patients with activating mutations in the EGFR gene and low c-MET levels seemed to benefit more from the combination in terms of progression free survival, 
indicating that c-MET/HGF inhibition may delay the rise of EGFR TKI resistance in this specific population of lung cancer patients. Nevertheless, the low number of patients included in the subgroup analyses precludes any firm conclusion.

The phase II trial with ficlatuzumab did not reach its primary endpoint but its exploratory biomarker analysis provided important directions for future studies with this agent. In our opinion, anti-MET agents should be explored mainly in three groups of NSCLC patients (Figure 2): (1) In EGFR TKI naïve patients harboring EGFR mutations in combination with EGFR TKI. Because MET amplification is one of the most relevant mechanisms involved in EGFR TKI resistance, ${ }^{13,74}$ it is possible that combining an EGFR TKI with an anti-MET agent leads to a delay in tumor progression; (2) In EGFR wild-type patients with high MET expression or MET gene amplification. MET gene amplification is a rare event in NSCLC, occurring in approximately $5 \%$ of cases. ${ }^{75}$ Data with onartuzumab, another anti-MET antibody, suggested that this agent in combination with erlotinib is more effective than erlotinib alone in high MET expressing patients. ${ }^{18}$ In a phase II randomized trial, tivantinib, a small molecule MET inhibi-
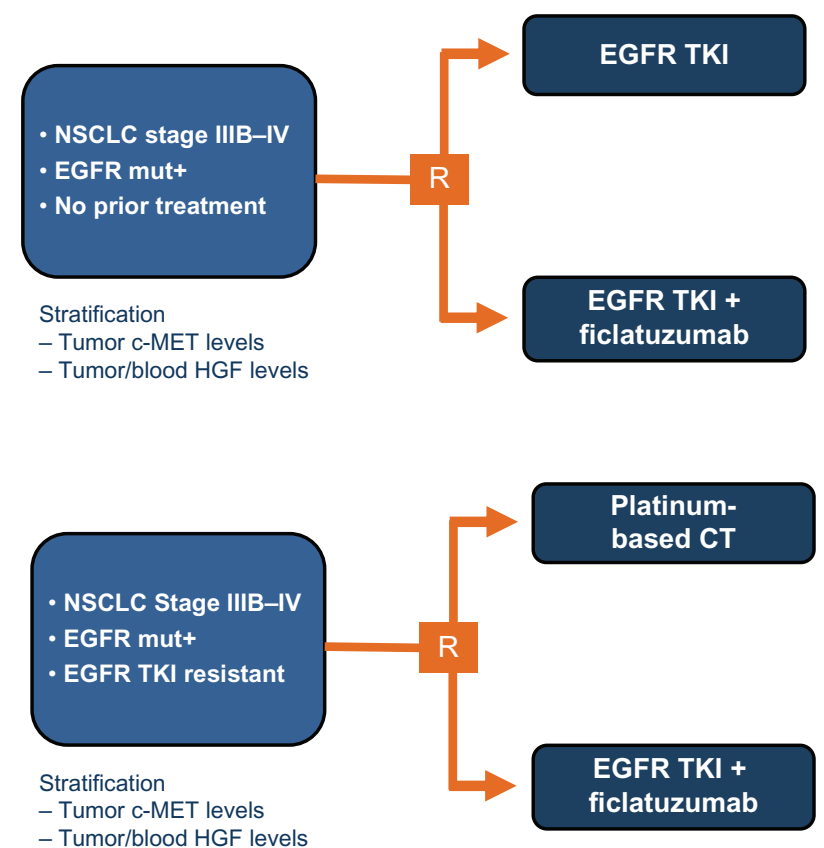

- Tumor/blood HGF levels

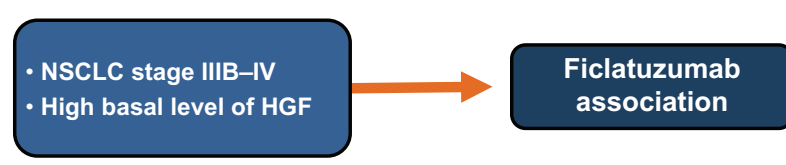

Figure 2 Future possible study designs for ficlatuzumab clinical development. Abbreviations: NSCLC, non-small cell lung cancer; EGFR, epidermal growth factor receptor; TKI, tyrosine kinase inhibitor; MET, mesenchymal-epithelial transition receptor; HGF, hepatocyte growth factor; CT, chemotherapy. tor, significantly delayed tumor progression when combined with erlotinib in MET amplified patients. ${ }^{23}$ Overall, data with anti-MET agents indicate that this class of drugs is potentially active in patients selected on the basis of MET expression or gene copy number; and (3) In patients with acquired resistance to EGFR TKI. Preclinical models showed that the combination of an irreversible EGFR TKI with an anti-MET agent is more effective than an anti-MET agent alone in NSCLC cell lines with acquired resistance to reversible EGFR TKI. ${ }^{12}$ Moreover, we observed that high levels of MET amplification, known to be associated with gefitinib resistance in vitro, rarely occurs in untreated NSCLC, irrespective of EGFR status, and that it may develop only under therapeutic pressure, leading to the conclusion that, in EGFR TKI naïve patients, the level of genomic gain for $M E T$ is not increased enough to impact response to TKI. This finding has clinical implications since support for anti-MET strategies should be focused particularly on EGFR TKI resistant patients, where MET gene gain is more frequently observed and can drive tumor resistance. ${ }^{75}$

\section{Conclusion}

The treatment of advanced NSCLC has deeply changed during the last decade and is rapidly moving toward personalized medicine. Biomarker analysis is becoming more and more important for defining prognosis and for offering the best treatment to our patients. c-MET and HGF have emerged as important biomarkers in NSCLC and other malignancies. Ficlatuzumab is a monoclonal antibody directed against HGF with promising preclinical activity; so far it has not been confirmed in clinical trials. To date, only data from a phase II trial are available and additional studies are planned. Nevertheless, accurate patient selection is of crucial relevance for understanding the real benefit produced by the drug and for offering our patients new therapies positively impacting on survival.

\section{Acknowledgment}

In part supported by the Italian Association for Cancer Research (AIRC) and Associazione Oncologia Traslazionale (AOT).

\section{Disclosure}

The authors report no conflicts of interest in this work.

\section{References}

1. Jemal A, Bray F, Center MM, Ward E, Forman D. Global cancer statistics CA Cancer J Clin. 2011;61:69-90.

2. Lynch TJ, Bell DW, Sordella R, et al. Activating mutations in the epidermal growth factor receptor underlying responsiveness of non-small-cell lung cancer to gefitinib. $N$ Engl J Med. 2004;350:2129-2139. 
3. MokTS, Wu YL, Thongprasert S, et al. Gefitinib or carboplatin-paclitaxel in pulmonary adenocarcinoma. $N$ Engl J Med. 2009;361:947-957.

4. Lee JS, Park K, Kim S-W, et al. A randomized phase III study of gefitinib (IRESSA) versus standard chemotherapy (gemcitabine plus cisplatin) as a first-line treatment for never-smokers with advanced or metastatic adenocarcinoma of the lung. JThor Oncol. 2009;4(Suppl 19): Abstract PRS 4.

5. Mitsudomi T, Morita S, Yatabe Y, et al. Gefitinib versus cisplatin plus docetaxel in patients with non-small-cell lung cancer harbouring mutations of the epidermal growth factor receptor (WJTOG3405): an open label, randomised phase 3 trial. Lancet Oncol. 2010;11:121-128.

6. Maemondo M, Inoue A, Kobayashi K, et al. Gefitinib or chemotherapy for non-small-cell lung cancer with mutated EGFR. $N$ Engl J Med. 2010;362:2380-2388.

7. Zhou CC, Wu YL, Chen G, et al. Erlotinib versus chemotherapy as first-line treatment for patients with advanced EGFR mutation-positive non-small-cell lung cancer (OPTIMAL, CTONG-0802): a multicentre, open-label, randomised, phase 3 study. Lancet Oncol. 2011;12: 735-742.

8. Rosell R, Carcereny E, Gervais R, et al. Erlotinib versus standard chemotherapy as first-line treatment for European patients with advanced EGFR mutations-positive non-small cell lung cancer (EURTAC) a multicenter, open-label, randomized phase 3 trial. Lancet Oncol. 2012;13:239-246.

9. Yang JC-H, Schuler MH, Yamamoto N, et al. LUX-Lung 3: a randomized, open-label, phase III study of afatinib versus pemetrexed and cisplatin as first-line treatment for patients with advanced adenocarcinoma of the lung harboring EGFR-activating mutations. J Clin Oncol. 2012;30(Suppl):Abstract LBA7500.

10. Kwak EL, Sordella R, Bell DW, et al. Irreversible inhibitors of the EGF receptor may circumvent acquired resistance to gefitinib. Proc Natl Acad Sci U SA. 2005;102:7665-7670.

11. Kobayashi S, Boggon TJ, Dayaram T, et al. EGFR mutation and resistance of non-small-cell lung cancer to gefitinib. $N$ Engl $J$ Med. 2005;352:786-792.

12. Balak MN, Gong Y, Riely GJ, et al. Novel D761Y and common secondary T790M mutations in epidermal growth factor receptor-mutant lung adenocarcinoma with acquired resistance to kinase inhibitors. Clin Cancer Res. 2006;12:6494-6501.

13. Engelman JA, Zajnullahu K, Mitsudomi T, et al. MET amplification leads to gefitinib resistance in lung cancer by activating ERBB3 signaling. Science. 2007;316:1039-1043.

14. Sequist LV, Waltman BA, Dias-Santagata D, et al. Genotypic and histological evolution of lung cancers acquiring resistance to EGFR inhibitors. Sci Transl Med. 2011;3:75ra26.

15. Wang W, Li Q, Yamada T, et al. Crosstalk to stromal fibroblasts induces resistance of lung cancer to epidermal growth factor receptor tyrosine kinase inhibitors. Clin Cancer Res. 2009;15:6630-6638.

16. Xu L, Kikuchi E, Xu C, et al. Combined EGFR/MET or EGFR/ HSP90 inhibition is effective in the treatment of lung cancers codriven by mutant EGFR containing T790M and MET. Cancer Res. 2012;72: 3302-3311.

17. Janjigian YY, Smit EF, Horn L, et al. Activity of afatinib/cetuximab in patients (pts) with EGFR mutant non-small cell lung cancer (NSCLC) and acquired resistance (AR) to EGFR inhibitors. Ann Oncol. 2012;23(Suppl 9):ix401:Abstract 12270.

18. Spigel DR, Ervin TJ, Ramlau R, et al. Final efficacy results from OAM4558 g, a randomized phase II study evaluating MetMAb or placebo in combination with erlotinib in advanced NSCLC. $J$ Clin Oncol. 2011;29(Suppl):Abstract 7505.

19. Kwak EL, Camidge DR, Clark J, et al. Clinical activity observed in a phase I dose escalation trial of an oral c-met and ALK inhibitor, PF-02341066. J Clin Oncol. 2009;27(Suppl):Abstract 3509.

20. Eder JP, Vande Woude GF, Boerner SA, LoRusso PM. Novel therapeutic inhibitors of the c-Met signaling pathway in cancer. Clin Cancer Res. 2009;15:2207-2214.
21. Yakes FM, Chen J, Tan J, et al. Cabozantinib (XL184), a novel MET and VEGFR2 inhibitor, simultaneously suppresses metastasis, angiogenesis, and tumor growth. Mol Cancer Ther. 2011;10:2298-2308.

22. Kollmannsberger CK, Hurwitz H, Vlahovic G, et al. Phase I study of daily administration of MGCD265 to patients with advanced malignancies (Study 265-101). J Clin Oncol. 2009;27(Suppl):Abstract e14525.

23. Sequist LV, von Pawel J, Garmey EG, et al. Randomized phase II study of erlotinib plus tivantinib versus erlotinib plus placebo in previously treated non-small-cell lung cancer. J Clin Oncol. 2011;29: 3307-3315.

24. Date K, Matsumoto K, Shimura H, Tanaka M, Nakamura T. HGF/NK4 is a specific antagonist for pleiotrophic actions of hepatocyte growth factor. FEBS Lett. 1997;420:1-6.

25. Tan E, Park K, Lim WT, et al. Phase Ib study of ficlatuzumab (formerly AV-299), an anti-hepatocyte growth factor (HGF) monoclonal antibody (MAb) in combination with gefitinib (G) in Asian patients (pts) with NSCLC. J Clin Oncol. 2011;29(Suppl 15):Abstract 7571.

26. Ma PC, Maulik G, Christensen J, Salgia R. c-Met: structure, functions and potential for therapeutic inhibition. Cancer Metastasis Rev. 2003; 22:209-325.

27. Sattler M, Ma PC, Salgia R. Therapeutic targeting of the receptor tyrosine kinase Met. Cancer Treat Res. 2004;119:121-138.

28. Nakamura T, Nawa K, Ichihara A, Kaise N, Nishino T. Purification and subunit structure of hepatocyte growth factor from rat platelets. FEBS Lett. 1987;224:311-316.

29. Gohda E, Tsubouchi H, Nakayama H, et al. Human hepatocyte growth factor in plasma from patients with fulminant hepatic failure. Exp Cell Res. 1986;166:139-150.

30. Stoker M, Gherardi E, Perryman M, Gray J. Scatter factor is a fibroblast-derived modulator of epithelial cell mobility. Nature. 1987;327:239-242.

31. Jiang W, Hiscox S, Matsumoto K, Nakamura T. Hepatocyte growth factor/scatter factor, its molecular, cellular and clinical implications in cancer. Crit Rev Oncol-Hematol. 1999;29:209-248.

32. Matsumoto K, Date K, Ohmichi H, Nakamura T. Hepatocyte growth factor in lung morphogenesis and tumor invasion: role as a mediator in epithelium-mesenchyme and tumor-stroma interactions. Cancer Chemother Pharmacol. 1996;38 Suppl:S42-S47.

33. Comoglio PM, Boccaccio C. Scatter factors and invasive growth. Seminar Cancer Biol. 2011;11:153-165.

34. Zhang YW, Vande Woude GF. HGF/SF-met signaling in the control of branching morphogenesis and invasion. $J$ Cell Biochem. 2003;88: 408-417.

35. Nakashiro K, Hara S, Shinohara Y, et al. Phenotypic switch from paracrine to autocrine role of hepatocyte growth factor in an androgenindependent human prostatic carcinoma cell line, CWR22R. Am J Pathol. 2004;165:533-540.

36. Naldini L, Vigna E, Narsimhan RP, et al. Hepatocyte growth factor (HGF) stimulates the tyrosine kinase activity of the receptor encoded by the proto-oncogene c-MET. Oncogene. 1991;6:501-504.

37. Ma PC, Jagadeeswaran R, Jagadeesh S, et al. Functional expression and mutations of c-Met and its therapeutic inhibition with SU11274 and small interfering RNA in non-small cell lung cancer. Cancer Res. 2005;65:1479-1488.

38. Smolen GA, Sordella R, Muir B, et al. Amplification of MET may identify a subset of cancers with extreme sensitivity to the selective tyrosine kinase inhibitor PHA-665752. Proc Natl Acad Sci U S A. 2006;103:2316-2321.

39. Michieli P, Basilico C, Pennacchietti S, et al. Mutant Met-mediated transformation is ligand-dependent and can be inhibited by HGF antagonists. Oncogene. 1999;18:5221-5231.

40. Boccaccio C, Gaudino G, Gambarotta G, Galimi F, Comoglio PM. Hepatocyte growth factor (HGF) receptor expression is inducible and is part of the delayed-early response to HGF. J Biol Chem. 1994;269: 12846-12851. 
41. Tuck AB, Park M, Sterns EE, Boag A, Elliott BE. Coexpression of hepatocyte growth factor and receptor (Met) in human breast carcinoma. Am J Pathol. 1996;148:225-232.

42. Koochekpour S, Jeffers M, Rulong S, et al. Met and hepatocyte growth factor/scatter factor expression in human gliomas. Cancer Res. 1997;57:5391-5398

43. Navab R, Liu J, Seiden-Long I, et al. Co-overexpression of Met and hepatocyte growth factor promotes systemic metastasis in NCI-H460 non-small cell lung carcinoma cells. Neoplasia. 2009;11:1292-1300.

44. Okuda K, Sasaki H, Yukiue H, Yano M, Fujii Y. Met gene copy number predicts the prognosis for completely resected non-small cell lung cancer. Cancer Sci. 2008;99:2280-2285.

45. Cappuzzo F, Marchetti A, Skokan M, et al. Increased MET gene copy number negatively affects survival of surgically resected non-small-cell lung cancer patients. J Clin Oncol. 2009;27:1667-1674.

46. Toi M, Taniguchi T, Ueno T, et al. Significance of circulating hepatocyte growth factor level as a prognostic indicator in primary breast cancer. Clin Cancer Res. 1998;4:659-664.

47. Yamashita J, Ogawa M, Yamashita S, et al. Immunoreactive hepatocyte growth factor is a strong and independent predictor of recurrence and survival in human breast cancer. Cancer Res. 1994;54:1630-1633.

48. Taniguchi T, Kitamura M, Arai K, et al. Increase in the circulating level of hepatocyte growth factor in gastric cancer patients. $\mathrm{Br} J$ Cancer. 1997;75:673-677.

49. Gohji K, Nomi M, Niitani Y, et al. Independent prognostic value of serum hepatocyte growth factor in bladder cancer. J Clin Oncol. 2000;18:2963-2971.

50. Toiyama Y, Miki C, Inoue Y, Okugawa Y, Tanaka K, Kusunoki M. Serum hepatocyte growth factor as a prognostic marker for stage II or III colorectal cancer patients. Int J Cancer. 2009;125:1657-1662.

51. Bharti A, Ma PC, Maulik G, et al. Haptoglobin alpha-subunit and hepatocyte growth factor can potentially serve as serum tumor biomarkers in small cell lung cancer. Anticancer Res. 2004;24:1031-1038.

52. Seidel C, Børset M, Turesson I, Abildgaard N, Sundan A, Waage A. Elevated serum concentrations of hepatocyte growth factor in patients with multiple myeloma. The Nordic Myeloma Study Group. Blood. 1998;91:806-812.

53. Siegfried JM, Weissfeld LA, Singh-Kaw P, Weyant RJ, Testa JR, Landreneau RJ. Association of immunoreactive hepatocyte growth factor with poor survival in resectable non-small cell lung cancer. Cancer Res. 1997;57:433-439.

54. Onitsuka T, Uramoto H, Ono K, et al. Comprehensive molecular analyses of lung adenocarcinoma with regard to the epidermal growth factor receptor, K-ras, MET and hepatocyte growth factor status. J Thorac Oncol. 2010;5:591-596.

55. Hosoda H, Izumi H, Tukada Y, et al. Plasma hepatocyte growth factor elevation may be associated with early metastatic disease in primary lung cancer patients. Ann Thorac Cardiovasc Surg. 2012;18:1-7.

56. Ujiie H, Tomida M, Akiyama $H$, et al. Serum hepatocyte growth factor and interleukin- 6 are effective prognostic markers for non-small cell lung cancer. Anticancer Res. 2012;32:3251-3258.

57. Minuti G, Cappuzzo F, Duchnowska R, et al. Increased MET and HGF gene copy numbers are associated with trastuzumab failure in HER2positive metastatic breast cancer. Br J Cancer. 2012;107:793-799.

58. Turke AB, Zejnullahu K, Wu YL, et al. Preexistence and clonal selection of MET amplification in EGFR mutant NSCLC. Cancer Cell. 2010;17:77-88.

59. Yano S, Wang W, Li QI, et al. Hepatocyte growth factor induces gefitinib resistance of lung adenocarcinoma with epidermal growth factor receptor-activating mutations. Cancer Res. 2008;68:9479-9487.

60. Yano S, Yamada T, Takeuchi S, et al. Hepatocyte growth factor expression in EGFR mutant lung cancer with intrinsic and acquired resistance to tyrosine kinase inhibitors in a Japanese cohort. J Thorac Oncol. 2011;6:2011-2017.
61. Masago K, Togashi Y, Fujita S, et al. Clinical significance of serum hepatocyte growth factor and epidermal growth factor gene somatic mutations in patients with non-squamous non-small cell lung cancer receiving gefitinib or erlotinib. Med Oncol. 2012;29:1614-1621.

62. Kasahara K, Arao T, Sakai K, et al. Impact of serum hepatocyte growth factor on treatment response to epidermal growth factor receptor tyrosine kinase inhibitors in patients with non-small cell lung adenocarcinoma. Clin Cancer Res. 2010;16:4616-4624.

63. Han JY, Kim JY, Lee SH, Yoo NJ, Choi BG. Association between plasma hepatocyte growth factor and gefitinib resistance in patients with advanced non-small cell lung cancer. Lung Cancer. 2011;74: 293-299.

64. Witta SE, Gemmill RM, Hirsch FR, et al. Restoring E-cadherin expression increases sensitivity to epidermal growth factor receptor inhibitors in lung cancer cell lines. Cancer Res. 2006;66:944-950.

65. Thomson S, Buck E, Petti F, et al. Epithelial to mesenchymal transition is a determinant of sensitivity of non-small-cell lung carcinoma cell lines and xenografts to epidermal growth factor receptor inhibition. Cancer Res. 2005;65:9455-9462.

66. Fujita Y, Suda K, Kimura H, et al. Highly sensitive detection of EGFR T790M mutation using colony hybridization predicts favorable prognosis of patients with lung cancer harboring activating EGFR mutation. J Thorac Oncol. 2012;7:1640-1644.

67. Cappuzzo F, Janne PA, Skokan M, et al. MET increased gene copy number and primary resistance to gefitinib therapy in non-small cell lung cancer patients. Ann Oncol. 2009;20:298-304.

68. Okamoto W, Okamoto I, Tanaka K, et al. TAK-701, a humanized monoclonal antibody to hepatocyte growth factor, reverses gefitinib resistance induced by tumor-derived HGF in non-small cell lung cancer with an EGFR mutation. Mol Cancer Ther. 2010;9:2785-2792.

69. Stabile LP, Rothstein ME, Keohavong P, et al. Targeting of both the c-Met and EGFR pathways results in additive inhibition of lung tumorigenesis in transgenic mice. Cancers (Basel). 2010;2:2153-2170.

70. Elez E, Tabernero J, Prudkin L, et al. Pharmacodynamic (PD) pharmacokinetic (PK) study of ficlatuzumab (F), a monoclonal antibody (MAB) directed to the hepatocyte growth factor (HGF), in patients (Pts) with advanced solid tumors who have live metastases (Mets). Ann Oncol. 2012;23(Supp1 9):ix154:Abstract 443PD.

71. Meetze KA, Boudrow A, Connoly K, et al. Anti-tumor activity of SCH 900105 (AV299), an anti-HGF antibody, in non-small cell lung cancer models. Mol Cancer Ther. 2009;8(Suppl 12):Abstract C173.

72. Patnaik A, Weiss GJ, Papadopoulos K, et al. Phase I study of SCH 900105 (SC), an anti-hepatocyte growth factor (HGF) monoclonal antibody (MAb), as a single agent and in combination with erlotinib (E) in patients (pts) with advanced solid tumors. J Clin Oncol. 2010;28(Suppl):Abstract 2525.

73. Mok TSK, Park K, Geater SL, et al. A randomized phase (Ph) 2 study with exploratory biomarker analysis of ficlatuzumab $(\mathrm{F})$ a humanized hepatocyte growth factor (HGF) inhibitory MAB in combination with gefitinib (G) versus $\mathrm{G}$ in Asian patients (pts) with lung adenocarcinoma (LA). Ann Oncol. 2012;23(Suppl 9):ix391:Abstract 1198P.

74. Engelman JA, Janne PA. Mechanisms of acquired resistance to epidermal growth factor receptor tyrosine kinase inhibitors in non-small cell lung cancer. Clin Cancer Res. 2008;14:2895-2899.

75. Cappuzzo F, Jänne PA, Skokan M, et al. MET increased gene copy number and primary resistance to gefitinib therapy in non-small-cell lung cancer patients. Ann Oncol. 2009;20:298-304. 


\section{Publish your work in this journal}

Biologics: Targets \& Therapy is an international, peer-reviewed journal focusing on the patho-physiological rationale for and clinical application of Biologic agents in the management of autoimmune diseases, cancers or other pathologies where a molecular target can be identified. This journal is indexed on PubMed Central, CAS, EMBase, Scopus

and the Elsevier Bibliographic databases. The manuscript management system is completely online and includes a very quick and fair peerreview system, which is all easy to use. Visit http://www.dovepress. com/testimonials.php to read real quotes from published authors. 